\title{
Understanding Online Political Networks: The case of the far right and far left in Greece
}

\author{
Pantelis Agathangelou ${ }^{1}$, Ioannis Katakis ${ }^{1}$ Lamprini Rori $^{2}$, Dimitrios \\ Gunopulos ${ }^{1}$, and Barry Richards ${ }^{3}$ \\ 1 University of Athens \\ katak|dg@di.uoa.gr,pandelisagathangelou@gmail.com \\ 23 Bournemouth University \\ lrori@bournemouth.ac.uk \\ 3 Bournemouth University \\ brichards@bournemouth.ac.uk
}

\begin{abstract}
This paper examines the connectivity among political networks on Twitter. We explore dynamics inside and between the far right and the far left, as well as the relation between the structure of the network and the sentiment. The 2015 Greek political context offers a unique opportunity to investigate political communication in times of political intensity and crisis. We explore interactions inside and between political networks on Twitter in the run up to the elections of three different ballots: the parliamentary election of 25 January, the bailout referendum of 5 July, the snap election of 20 September; we, then, compare political action during campaigns with that during routinized politics.
\end{abstract}

\section{Introduction}

According to the echo chamber thesis, political networks on the internet are fragmented and limiting. Online political communication basically preaches to the converted with little or no possibility to influence opinions, spread new ideas, or ensure a plurality of views. If this is the case, exposure on the web is constrained to reinforcement inside more or less ideologically homogeneous communities, and to silence or polarization towards politically divergent networks. However, constant expansion in the use of social media platforms and fluidity in voter choices oblige us to re-examine the dynamics of political networks, particularly in contexts of extreme uncertainty and polarization. Moreover, the popularity of the echo chamber claim has neglected important functions and dynamics of

\footnotetext{
${ }^{4}$ This is an updated version of a paper published in the proceedings of the International Conference on Social Informatics. Changes have been made to the legends of Tables 1 and 2, to Figure 1 and to the References sections. For citing this article please use: Agathangelou P., Katakis I., Rori L., Gunopoulos D., Richards B., Understanding online political networks: the case of the far right and the far left in Greece, in Ciampaglia G.L., Mashhadi A., Yasseri T. (eds.), Social Informatics, 9th International Conference SocInfo 2017, Proceedings Part 1, LNCS 10539, pp. 162-177, 2017. DOI: 10.1007/978-3-319-67217-5 11
} 
online political networks such as the relation between structure of the network and discourse. Whereas, furthermore, we have investigated the types of political structures formed in social media, we know little about the online communication of the ideological edges of the political system. Psycho-social theories and political research on radicalism show that inter-group polarity and opposition are vital for solidifying intra-group identity and trust. Political and community conflict can be exacerbated by the behaviour of antagonistic parties even when this behaviour does not constitute an attempt to affect the outcome of the conflict by gaining advantage in influence or material position.

The Case of Greece. We examine a series of innovative hypotheses, by focusing on the case of Greece during the period of the great crisis which started in 2010, under the light of the wealth of possibilities that the new media revolution has opened for political action and communication. Greece has been the country firstly and most severely hit by the recent financial crisis in the EU. It received immense international financial aid, which has been followed by acute austerity measures[12] . As a result, big parts of the Greek society radicalized, which was often reflected on a dense protest cycle, violent and anti-systemic. Polarization and electoral volatility prevailed throughout a period of political instability, consecutive elections and negotiations with the bailout partners. The evolution of the party competition signaled a passage from an until 2009 centripetal democracy, to a centrifugal democracy formed by the earthquake elections of May 2012 to a polarized multi-party party system, which has been established ever since [8]. The dominant parties of the two-party system which existed since the 1980s collapsed; whereas the country experienced since then the meteoric rise of old minor or marginal political actors (SYRIZA, HA), as well as the emergence of a series of splinter parties, mainly radical (ANEL, LAE). We consider Greece as a unique product of the financial crisis, in the sense that since 2012 the third party in parliament is a neo-Nazi party, whereas the government in place since 2015 , is a coalition of the far left and the far right [20]. Greece, hence, brings topical phenomena and trends of European politics to their limits.

The contributions of this paper can be summarized in the following points:

- We study the online blueprint of radicalization in times of crises; how the emergence of new cleavages is reflected in the online political world and what dynamics it produces between different political spaces.

- We bring into discussion the online polarization in multi-party systems, which covers an existing lacuna stemming from the fact that most relevant studies focus on the US two-party system.

- We propose and utilize a novel method for advocates' identification. An algorithm that assigns citizens to political spaces based on their activity in social media.

- We collect two large sets of twitter messages that we break into three time windows relevant to our research. Our method permits to capture variation of political networks over time, as well as change in individual stances.

- We test our hypotheses by introducing measures of political cohesion, communication density and network visualizations. 


\section{Related Work}

In this section we overview theoretical discussions relevant to our research questions and hypotheses.

Communication, Information and Influence In contemporary democratic environments, citizens receive information mainly through interpersonal communication, mass media and digital media. Despite tendency of interpersonal communication to reinforce confirmed beliefs and relations with like-minded people, disagreement perseveres, mainly in low-density networks, that leave room for relatively distanced acquaintances. Mass media are more likely to expose individuals to diverse information in comparison to face-to-face discussions [16]. Nonetheless, the public is not passive when exposed to the media. Selective exposure research has pointed that individuals are driven in media channels or information, which match their beliefs [2], whilst secluding others with which they disagree. Because of their choice-enhancing capacities and the algorithms which define suggestions on who to follow [6], social media are said to be more conducive to ideological self-segregation.

Political Homophily in Social Media Political discussions on social media are said to take place inside echo chambers [4], which correspond to political sub-groups characterized by a broad ideological homogeneity. Among a series of parameters, ideological stances affect the levels of individual and group fragmentation. The echo chamber thesis is not, however, uncontested. Holbert, Garrett and Gleason argued that the fact that digital political communication increases individual exposure to like-minded ideas and sources of information, this does not mean that the same individuals avoid [10] or can totally filter out contrary or different viewpoints. Social media facilitate contact with diverse and heterogeneous political opinions unintentionally, when individuals use them for nonpolitical reasons [24], since information circulates across networks on various, different occasions [3]. A recent strand of research brings in discussion the importance of the nexus between online and offline political discussions, as well as elements stemming from political psychology theories, like the level of openness of an individual and the level of political interest [22].

Polarization and Political Extremism Ideology is the driving force in echo chambers formation. In a systematic large scale comparative research of fragmentation on Twitter between individuals, groups and group-dyads, [5] finds that parties networks which are distanced in ideological terms, interact less and that echo chambers are mostly likely formed by users and groupings positioned at the extreme ends of the ideological scale. Under certain circumstances, like in periods of financial crises and political tensions, individuals facing relative deprivation or grievances of various kinds can radicalize towards political extremism. Ideology, emotions [7], as well as trigger events and socialization environments can play a role in embracing extremist views or actions. Extremist and terrorist groups use the internet for a myriad of purposes, including the dissemination of propaganda, the recruitment of members and the development of operational planning. While right-wing extremist communities have had an online presence for years through dedicated websites, there has been an increased activity on so- 
cial media in recent years. Nevertheless, the extent to which the Internet affects radicalization into violence is contested.

The Decline of the Left-Right Ideological Distinction and the Rise of New Cleavages Since the outbreak of the financial crisis, the collapse of the old twopartyism and the rise of radical and extreme parties, a new, more polarized bipolar system has restructured political conflicts and expressed emerging issues [8]. Hence, from 2010 until the summer of 2015, in a context of unprecedented polarization, parties of the centre-right and the centre-left have supported bailout policies, the European currency and stay in the EU, whereas parties of the far right and the far left shared anti-bailout stances, populism and Euroscepticism, which for some amongst them turned to fierce hostility towards the EU and the desire of adopting the national currency. A paradoxical political alliance has been the coalition government which was formed in January 2015 between the radical left party of SYRIZA (Coalition of the Radical Left) and the far right party of ANEL (Independent Greeks) [20]. Research on polarization in social media cannot neglect those important shifts in party competition and political alliances. Measures of fragmentation should take into account at the same time the old Left-Right divide and the new bailout-anti-bailout conflict, and hence examine the frequency and nature of interactions of political networks formed alongside those lines of divisions.

Study of Discussions in Social Media [14] study on-line discussions in order to identify patterns in how German politicians acted in social media during the 2013 elections. Their main data source is the Twitter network. [19] present a study of Twitter during the Brazilian protests of 2013. Similar to our work, sentiment analysis and user activity is the tool for exploring the data. The authors observed that activity and sentiment peaks coincide with the days of the protests. [23] infer the political signature of the Twitter users by applying a walking algorithm over the social graph. The output of the method is the estimated distribution of political preference over the eight Flemish political parties. A case study on the 2014 national elections is presented. [4] discuss the way Twitter reacts on major political and non-political events. Their main conclusion is that polarization in social media is limited in comparison with what has been observed by previous work.

Identifying Advocates In [18] the authors build a framework for identifying advocates for political campaigns in social media. The framework models message strategies, propagation strategies and community structure. These three elements comprise the features that are utilized as input in data classification algorithms like Linear Discriminant Analysis. The authors observe that the proposed frame-work outperforms a set of baseline methods (random assignment, total number of tweets as a feature, bag-of-words) in identifying advocates. Experiments include two use cases utilizing Twitter data. The first regards elections in India while the second is about gun rights in the United States. [9] investigate the possibility of automatically identifying peoples voting intentions for the Scottish Independence Referendum by analyzing their Tweets. 
Table 1: Total number of unfiltered tweets collected from timelines of candidates and potential advocates.

\begin{tabular}{rcccccccc|c}
\hline Period KKE & ANTARSIA & LAE & SYRIZA PASOK POTAMI & ND & HA & ANEL & TOTAL \\
\hline 1st $0.04 \mathrm{M}$ & $0.16 \mathrm{M}$ & - & $1.22 \mathrm{M}$ & $0.89 \mathrm{M}$ & $0.88 \mathrm{M}$ & $1.55 \mathrm{M}$ & $0.13 \mathrm{M}$ & $0.66 \mathrm{M}$ & $\mathbf{5 . 5 1 M}$ \\
2nd-3rd 0.05M & $1.07 \mathrm{M}$ & $0.41 \mathrm{M}$ & $0.63 \mathrm{M}$ & $1.20 \mathrm{M}$ & $0.71 \mathrm{M}$ & $1.84 \mathrm{M}$ & $0.14 \mathrm{M}$ & $0.56 \mathrm{M}$ & $\mathbf{6 . 6 0 M}$ \\
\hline
\end{tabular}

Opinion Mining and Sentiment Analysis In recent years, many research studies focus on the problem of sentiment lexicon construction. Most of them utilize some opinion seed words and word similarities to construct the sentiment lexicon. According to the way in which the word similarities are obtained, these studies can be categorized into three types of approaches: a) the semantic thesaurus based approaches [11], [13] b) the corpus based approaches [21], [15] , and c) the pattern based approaches [17]. In this paper we will utilize a tool developed by our research team that falls into the third category [1].

\section{Data Collection and Advocate's Identification}

\subsection{Data Collection}

In order to test the hypotheses under study, we collected three large sets of twitter datasets that were relevant to our research. What is necessary for our data collection is a pool of leaders (representatives of each space) that will aid in identifying the political networks (i.e. the advocates of each political space). Time Periods. In order to capture variation over time and between periods of different political intensity, we introduced two 3-month periods of political campaigns and different kinds of elections and one period of routinized politics.

- First Period: The important political events of the first period (01.11.2014 30.01.2015) are the presidential election in parliaments which led to a stalemate and provoked an early parliamentary election; the victory of SYRIZA in the January 2015 election and the coalition government with ANEL.

- Second Period: The second period (21.06.2015-21.09.2015) is the most polarized among the three, dominated by the referendum for the bailout agreement, the enduring negotiations of the Greek government with the European partners, intense and consecutive parliamentary procedures and the snap parliamentary election of September 2015.

- Third Period: In the third period (01.03.2016 - 30.05.2016) the main events where the refugee crisis and the new austerity measures. Given the fact that no elections took place between the 2nd and the 3rd period, neither during the third, the political networks are formed by the same initial set of political candidates.

A set of statistics regarding the three periods can be seen in Table 3, Table 1 (tweets sent by users through their complete timelines) and Table 2 (tweets sent by users through the specific time windows).

Party Candidates (leaders). We utilized the set of official political candidates running for the parliamentary elections in our different periods of study who 
Table 2: Number of tweets sent by confirmed advocates per period under study.

\begin{tabular}{c|ccccccccc|c}
\hline Period & KKE & ANTARSIA & LAE & \multicolumn{2}{c}{ SYRIZA PASOK POTAMI } & ND & HA & ANEL & TOTAL \\
\hline 1st & $.004 \mathrm{~K}$ & $3.3 \mathrm{~K}$ & - & $28.54 \mathrm{~K}$ & $11.31 \mathrm{~K}$ & $10.47 \mathrm{~K}$ & $14.23 \mathrm{~K}$ & $.95 \mathrm{~K}$ & $14.77 \mathrm{~K}$ & $\mathbf{8 3 . 5 7 K}$ \\
2nd & $.79 \mathrm{~K}$ & $7.22 \mathrm{~K}$ & $9.82 \mathrm{~K}$ & $30.12 \mathrm{~K}$ & $26.07 \mathrm{~K}$ & $28.09 \mathrm{~K}$ & $32.93 \mathrm{~K}$ & $5.48 \mathrm{~K}$ & $20.8 \mathrm{~K}$ & $\mathbf{1 6 1 . 3 2 K}$ \\
3rd & $3.14 \mathrm{~K}$ & $9.68 \mathrm{~K}$ & $13.78 \mathrm{~K}$ & $31.21 \mathrm{~K}$ & $40.68 \mathrm{~K}$ & $29.26 \mathrm{~K}$ & $59.1 \mathrm{~K}$ & $6.56 \mathrm{~K}$ & $22.45 \mathrm{~K}$ & $\mathbf{2 1 5 . 8 4 K}$ \\
\hline
\end{tabular}

Table 3: Political Candidates with Twitter Accounts, and Confirmed Advocates Extracted for Each Party

\begin{tabular}{|c|c|c|c|c|c|c|c|c|c|}
\hline \multirow{2}{*}{\multicolumn{2}{|c|}{ Party }} & & \multicolumn{2}{|c|}{ 1st Period } & \multirow[b]{2}{*}{$\begin{array}{l}\text { Confirmed } \\
\text { Advocates }\end{array}$} & \multirow[b]{2}{*}{ Candidates } & \multicolumn{2}{|c|}{ 2nd, 3rd Periods } & \multirow[b]{2}{*}{$\begin{array}{l}\text { Confirmed } \\
\text { Advocates }\end{array}$} \\
\hline & & & Accounts & Percentag & & & Accounts & Percentage & \\
\hline 1 & KKE & 413 & 6 & $1.45 \%$ & 41 & 482 & 8 & $1.66 \%$ & 48 \\
\hline & NTARSIA & 366 & 42 & $11.48 \%$ & 158 & 341 & 39 & $11.44 \%$ & 1119 \\
\hline 3 & LAE & - & - & - & - & 698 & 61 & $8.74 \%$ & 420 \\
\hline 4 & SYRIZA & 433 & 180 & $41.57 \%$ & 1485 & 424 & 136 & $32.08 \%$ & 866 \\
\hline 5 & PASOK & 399 & 108 & $27.07 \%$ & 680 & 406 & 126 & $31.03 \%$ & 842 \\
\hline 6 & POTAMI & 405 & 113 & $27.90 \%$ & 1087 & 406 & 103 & $25.37 \%$ & 1003 \\
\hline 7 & ND & 425 & 242 & $56.94 \%$ & 1514 & 423 & 241 & $56.97 \%$ & 1845 \\
\hline 8 & $\mathrm{HA}$ & 388 & 65 & $16.75 \%$ & 130 & 320 & 56 & $17.50 \%$ & 142 \\
\hline 9 & ANEL & 407 & 92 & $22.60 \%$ & 695 & 404 & 78 & $19.31 \%$ & 560 \\
\hline
\end{tabular}

had a Twitter account. Some statistics related to the political candidates can be found in Table 3. Note that we manually identified the twitter accounts of the candidates since such list does not exist. Due to space limitation, we do not present the names of the candidates and their respective twitter accounts.

Definition of Political Spaces. Here we present the Greek political parties that we classified in three political spaces (Far Right, Center, Far left). The abbreviations below are used throughout the paper.

- Far Right: - ANEL (Independent Greeks): Splinter party of ND (New Democracy), founded in 2012. Populist, conspirationanist, nationalist, anti-bailout,

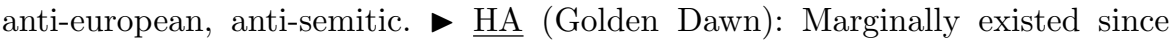
1980s. Extremist, ultra-nationalist, racist, nazi-friendly, violent, welfare chavinism, anti-establishment.

- Far Left: SYRIZA (Coalition of the Radical Left): Party of the radical left, since 2004. Ethno-populist, eurosceptic, anti-bailout, conspirationist. KKE (Communist Party of Greece): Orthodox Communist Party, since 1920s. - LAE (Popular Unity): Splinter party of SYRIZA, since September 2015. AntiEuroepan, pro-national currency, anti-German, pro-Russian. ANTARSIA (Anticapitalist Left Cooperation for the Overthrow): Stalinist, inclined to violent activism, antifascist, leftist.

- Center: We have grouped as political parties belonging to the center: PASOK (Panhellenic Socialist Movement): Party of the centre-left, existing since 1974, pro-European, pro-bailout. POTAMI (River): Social-liberal party of the centre, founded in 2014, pro-European, pro-bailout. $\rightarrow$ NEA DEMOCRATIA (New Democracy): Centre-right party, founded in 1974, pro-European, pro-bailout. 


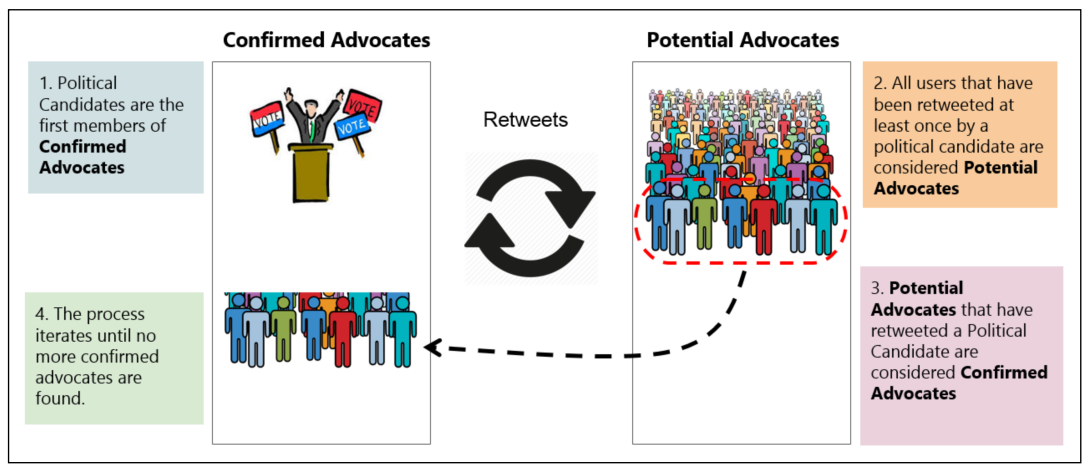

Fig. 1: Advocate's Identification

\subsection{Advocate's Identification}

In order to illustrate and analyze the political network we identify users that advocate one or more of the political spaces defined. To do this, we use the retweets as an indication of endorsement. Based on this assumption we followed the steps below:

- Initially, we identify a pool of 'Potential Advocates' $(P A)$. These are the users that have been retweeted by the Political Candidates $(P C$ - see previous section), at least once.

- If the Potential Advocates have retweeted back the Political Candidates (Leaders) then we consider them as 'Confirmed Advocates' (CAs) (this means that we are confident that these are members of the same political space as the one they have been endorsed through the re-tweet).

- In order to find more Confirmed Advocates we follow the same process in an iterative fashion. After the first iteration, we seek to see if a Potential Advocate has been re-tweeted by a Political Candidate or a Confirmed Advocate. When we find new Confirmed Advocates we add them in the pool, and so forth. The process stops when no new Confirmed Advocates are found.

An illustration of these steps can be seen in Figure 1. From our experimental evaluation we observed that the process stops after two or three iterations. The reliability of the above algorithm has been assessed by manual investigation and we confirmed that it accurately extracts advocates of all political spaces.

Collected Data. Data collection was operated with the following algorithm:

1. Identify the Twitter accounts of the political candidates (leaders).

2. Collect messages from their timelines (up to 2000 messages)

3. Collect the twitter followers that leaders have ReTweeted at least once (PAs).

4. Collect the timelines of the PAs (up to 2000 messages).

5. Based on the full timelines of leaders and PAs, scan for ReTweets and apply the Advocate Identification algorithm (see Figure 1) in order to extract the list of confirmed advocates. 
6. The confirmed advocates are the users that we utilize to illustrate the interactions among the political spaces. We filter out all messages not belonging to the three periods under study.

In Tables 1, 2 and 3 we present details about the collected data. Interestingly, there is a significant variation in the number of candidates who owned a twitter account (ranging from 1-60\%) among different political parties. The number of advocates per network is changing over time, which means that networks are dynamic and not static, reflecting the off-line political fluidity of the context under study.

\section{Hypotheses Under Investigation}

In this paper, we will investigate the following hypotheses:

- H1. In line with findings which show that individuals and groupings which sit at the extreme ends of the ideological scale are particularly likely to form echo chambers, we expect to find strong levels of cohesion on the edges of the political network (echo chambers' hypothesis).

- H2. Given the level of polarization that emerged over the financial crisis, we expect to find levels of interaction of radical actors which do not only reflect traditional ideological proximity, but also coalitions formed around emerging divides (hypothesis on convergence over new divisions).

- H3. Given the ideological differences regarding the hierarchy between the extreme edges of the party system, we expect that far right networks will display higher level of internal cohesion, but lower levels of internal interaction than far left communities. (intra-group hierarchy hypothesis)

- H4. We expect to find intensity of sentiment to be stronger in extremist and radical networks. (differences in sentiment)

\section{1 (H1) Echo Chambers}

We introduce the metric of internal cohesion, in order to calculate the level of interaction in the three periods under study. By internal cohesion we define the proportion of interaction which targets the members of the same political network. More specifically, the internal cohesion of party $i$ is defined as follows: Given a set of political parties $P=\left\{p_{1} \cup \ldots \cup p_{N}\right\}$ where $N$ is the total number of parties, and $U$ a set of users belonging to all political parties:

$$
\text { Internal Cohesion }_{i}=\frac{\text { Interactions of all users } u_{j} \in p_{i} \text { with users } u_{k} \in p_{i}}{\text { Interactions of all users } u_{k} \in P \text { with users } u_{j} \in p_{i}}
$$

This metric counts cohesion on a relative scale and can, thus, account for 'echo chamberness' by comparing levels of cohesion between political networks. In order to explore the kinds of interactions, we examined separately the cohesion of communication by replies and retweets. We consider replies to denote 


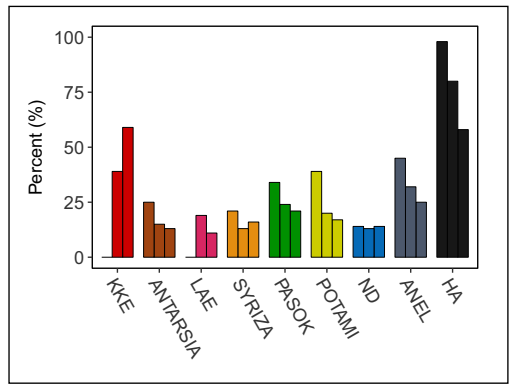

(a) Replies' Cohesion

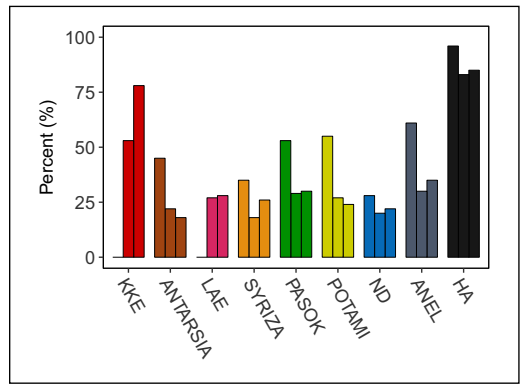

(b) Retweets' Cohesion

Fig. 2: Evolution of Internal Cohesion - 1st, 2nd, 3rd period for each party

discussions or exchanges of opinions, whereas retweets to manifest agreement or endorsement of ideas.

As Figure 2 depicts, retweets display higher levels of cohesion than replies, for all political networks. This finding testifies the different use that advocates attribute to those two modes of communication and is in line with our assumption on the matter. Networks at the edges of the party system are more cohesive than networks at the centre. HA and ANEL on the far right and KKE and ANTARSIA are the most cohesive political networks in the three periods under study. The right-wing extremist party (HA) is the one which mostly resembles to an echo chamber, followed by the orthodox communist (KKE). We can thus tentatively validate our first hypothesis. Nonetheless, interestingly the overall trend for cohesion is to decrease over time for all parties except from KKE, which means that political networks are not static; they develop particular dynamics and in our case study, they tend to lose degrees of 'echo chamberness', especially from the first to the second period, that political intensity and polarization increased. Hence, polarization can reduce cohesion of the most introvert political networks.

\section{2 (H2) Alliances over new divisions}

In Figure 3 we observe the retweet networks (i.e. who retweeted whom) in the three periods under study. Nodes represent the advocates of each space and the edges are the retweets. Different colours in the nodes illustrate the different political parties. The size of the nodes shows the level of degree (indegree and outdegree interactions). In other words the size is indicative of how active the advocate is in terms of retweets. In order to analyze these results, we defined the measures of density and interactivity of a network (see Equations below). The first one illustrates how active the users are as a network and the second calculates the degree in which the main communication is channeled from a small number of users (active) to their followers (inactive users). 


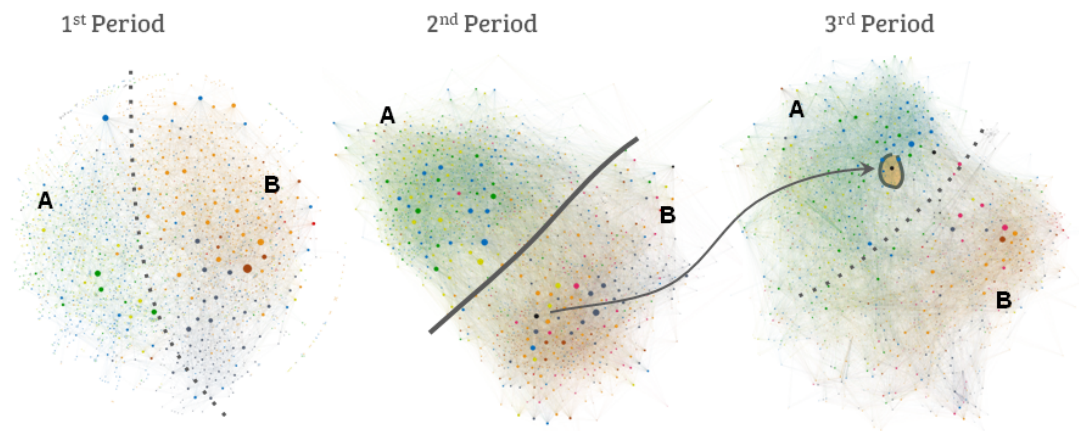

Fig. 3: Retweets' Political Network

Table 4: Density \& Interactivity of the Political Network of Figure 3

\begin{tabular}{|c|c|c|c|c|c|}
\hline \multicolumn{6}{|c|}{ Period Messages Senders Recipients Density Interactivity } \\
\hline 1st & 24588 & 732 & 1957 & 9.14 & 0.27 \\
\hline 2nd & 104922 & 939 & 3787 & 22.20 & 0.20 \\
\hline 3rd & 117972 & 1389 & 4221 & 21.03 & 0.25 \\
\hline
\end{tabular}

$$
\begin{gathered}
\text { density }=\frac{\text { number of messages }}{\text { total number of users }} \\
\text { interactivity }=\frac{\text { number of users sending messages }}{\text { total number of users }}
\end{gathered}
$$

Density of communication increases considerably from the first period to the second: from 9.14 messages per user to 22.20 , whereas it remains almost equally dense in the third. Interactivity is nonetheless low in the three periods under study, reaching its lowest point during the second, when $20 \%$ of users in the networks retweet others. Overall, polarization increased density of discussions but did not foster interactivity between users.

During the first period, we can observe two sub-areas. Sub-area A is more mixed than B and portrays retweets of advocates of PASOK, POTAMI and ND. All three are pro-bailout or pro-EU parties. In sub-area B we can observe parties of the far right and the far left, which are closer than with parties of sub-area A, but distinct party spaces. In the second and the third period, the network is denser and the communication polarized. During the second period, we can distinguish a fragmented network in two distanced clusters. The first cluster still contains the pro-bailout parties, the connectivity of which is much bigger, whereas the second cluster pertains the anti-bailout or anti-EU parties (HA, ANEL, SYRIZA, LAE, KKE, ANTARSIA), which have now merged. As a result, we can no longer see distinct party spaces. During the third period, the network is still divided and clustered, the main difference with the second period being 
the position of the right-wing extremist HA, which has moved away from the probailout camp. This is due to the fact that during the third period, the agenda was largely dominated by the refugee crisis, which is an issue of division between the far right and the far left. Overall, the visualization of the network following their retweets' traces shows us that there are changes in the structure of the network depending on the political context. As polarization increased from the first to the second and the third period, communication became more fragmented, with its structure moving from party-oriented to issue-oriented. Polarization facilitated convergence between ideological divergent spaces and reinforced the merging of the extremes of the party networks.

What we generally observe is that party advocates not only retweet the "usual suspects" - their ideological neighbours following the Left-Right axis - but also that they retweet their allies inside the pro-bailout or the anti-bailout camp.

\section{3 (H3) Intra-Group Hierarchy}

The different levels of internal cohesion are portrayed in Figure 2. Strong levels of cohesion have been found on networks belonging to the edges of the party systems. HA displays the highest internal cohesion among all party networks, followed by KKE. Even though the far right ANEL also presents relatively higher cohesion than parties of the far left or the centre, the differences are small. Hence, higher levels of internal cohesion seem to relate with spaces associated with totalitarian ideologies. In order to compare how communication is diffused inside the edges of the political system online, we divided the network in three ideological spaces: the far left, the centre and the far right. For each space, we portray the internal architecture, the structure of the network, as it is formed by the replies and the retweets of users targeting advocates of the same ideological space. Figure 5 depicts the visualization of the diffusion of communications flows inside each space. At first sight, the shape of the networks on the far right and the far left is fragmented, whereas connectivity seems homogeneously distributed for the political centre. On the far right, the right-wing extremist component (HA) seems hardly connected to the populist, radical one (ANEL), only via a few usersbridges. Fragmentation appears also on the far left, even though its different components do not figure so distanced as on the far right. In the centre, we can discern certain parts of the networks being more populated by distinct colours, which manifests conversations at the party-level, developed around prominent figures. Nonetheless, the political centre portrays a better connected and densely populated online network. Hence, ideology seems to correlate with the internal communication structure of neighbouring political networks.

By calculating the density and interactivity for each ideological space, we can compare the nature of communication inside each ideological space. Table 5 depicts the evolution of the two measures over time. Communication is denser among the far right in the first period and among the center in the second and the third. The intensity of discussions is dropping for the far left in the third period, most probably due to the capitulation of the government over the bailout agreement and the splinter inside the family of the far left. Overall polarization 


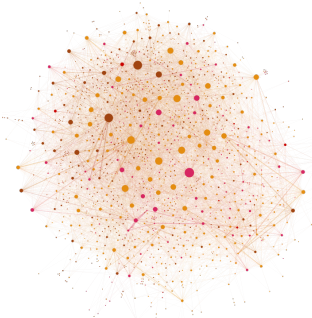

(a) Far Left

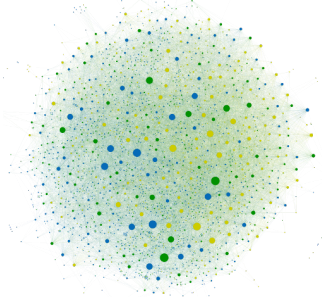

(b) Center

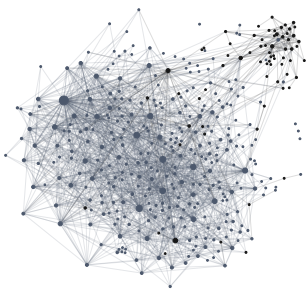

(c) Far Right

Fig. 4: Interaction Among Political Spaces' Groups during the 2nd Period

Table 5: Density \& Interactivity for the Politically Extreme Groups

\begin{tabular}{lrccccc}
\hline \multicolumn{3}{l}{ Period Political Group Messages Senders Recipients Density } & Interactivity \\
\hline \multirow{3}{*}{ 1st } & Far Left & 6269 & 600 & 473 & 5.84 & 0.56 \\
& Center & 8329 & 352 & 994 & 6.19 & 0.26 \\
& Far Right & 4121 & 99 & 232 & 12.45 & 0.30 \\
\hline \multirow{2}{*}{ 2nd } & Far Left & 23514 & 316 & 1309 & 14.47 & 0.19 \\
& Center & 52045 & 519 & 2121 & 19.71 & 0.20 \\
& Far Right & 7150 & 145 & 316 & 15.51 & 0.31 \\
\multirow{2}{*}{3 rd } & Far Left & 24173 & 411 & 1326 & 13.92 & 0.24 \\
& Center & 66694 & 805 & 2456 & 20.45 & 0.25 \\
& Far Right & 6737 & 194 & 364 & 12.07 & 0.35 \\
\hline
\end{tabular}

increased density of communications inside the three political spaces. Interactivity in the far left is the highest during the first period among the three political spaces, despite its low levels of density. The trend is reversed in the next two periods: the far right displays the highest levels of interactivity among the three political spaces. Our hypothesis is thus rejected. This means that polarization increased interactivity of the far right spectrum and communication is not hierarchical as we would expect, following the organizational norms of the far right party family.

\section{4 (H4) Differences between far right and far left sentiment}

To investigate this hypothesis we conducted sentiment analysis on the within network discussions. More specifically, we applied our opinion mining algorithms [1] to the messages sent (as replies) between users of the same political space. Our tool, DidaxTo [1], is able to extract the opinion words (terms like 'beautiful' or 'convenient') for any domain in an unsupervised fasinon. Opinion words can be positive or negative. Examples of opinion words discovered by DidaxTo for the given set of tweets are: 'charismatic', 'responsibility', 'solidarity' and 'unsustainability', 'overthrow', 'unconstitutional'.

Based on these, we calculated the sentiment of an individual tweet by subtracting the number of negative words from the number of positive words. If, for 
example, a tweet contains more positive words it is considered positive. Then we calculated the sentiment of each day by subtracting the negative tweets at that day from the positive ones. In Figures $5 \mathrm{a}, 5 \mathrm{~b}$ and $5 \mathrm{c}$ we expose the sentiment plots for each period and political space. The ' $y$ ' axes expresses the number of tweets per day and the color represents negative/positive sentiment; the size of the dot represents the absolute value of the sentiment. In the first period we recorded more 'extreme' days in terms of sentiment comparing to the other two periods since sentiment reaches values like +30 or +40 . In the second period we see that there is high activity during July in all political spaces, which was the most polarized period, due to the referendum and the enduring negotiations of the government with the EU. The most negative sentiment is expressed during that period. Overall, the sentiment is positive most of the time in all periods and spaces. However, the volume of negative sentiment is higher in the far left and the far right. This finding validates our hypothesis and is associated to the radical nature of those ideological spaces and the way this is reflected in their discourse.

\section{Conclusions}

Times of crises are also times of political reshuffling and realignment. In this study, we have shown that in periods of crises, online political networks are porous. Contrary to previous findings which considered political discussions taking place only inside echo chambers, we showed that political networks are not static neither solid, as political actors consider turbulence and volatility as structures of political opportunity in order to gain visibility, leverage and issueownership. This finding is particularly interesting for the radical and extremist actors: even through we have shown that their introvertness is higher compared to moderate networks, they tend to lose levels of cohesion when polarization increases. By focusing on the great Greek crisis at periods of different political intensity, we showed how emerging divisions related to the crisis affected the structure of the networks and facilitated convergence between the edges of political networks. Political networks evolved from party-oriented to issue-oriented. We showed that when electoral competition is not driven by the left-right divide, the online world absorbs the new cleavage. When delving into the structure of the network and the sentiment within the far right and the far left, no significant differences were found. Further research needs to be done in order to explore the impact of the agenda on the structure of political networks.

\section{Acknowledgement}

This work received funding from the European Union Horizon 2020 Programme (Horizon2020/2014-2020), under grant agreement 688380 and the FP7-PEOPLE2013-IEF Marie Curie fellowship project "Social media and resurgent ethnonationalism in Greece" (SMARTETHIC). 

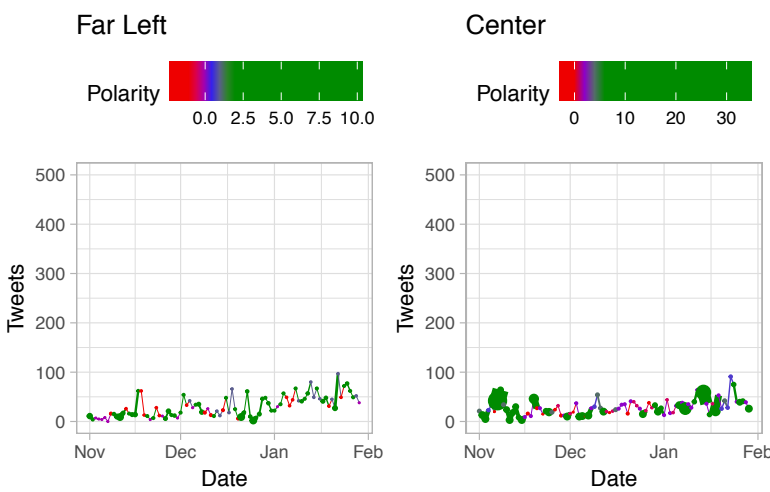

Far Right

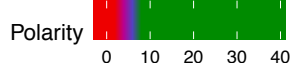

(a) 1st period
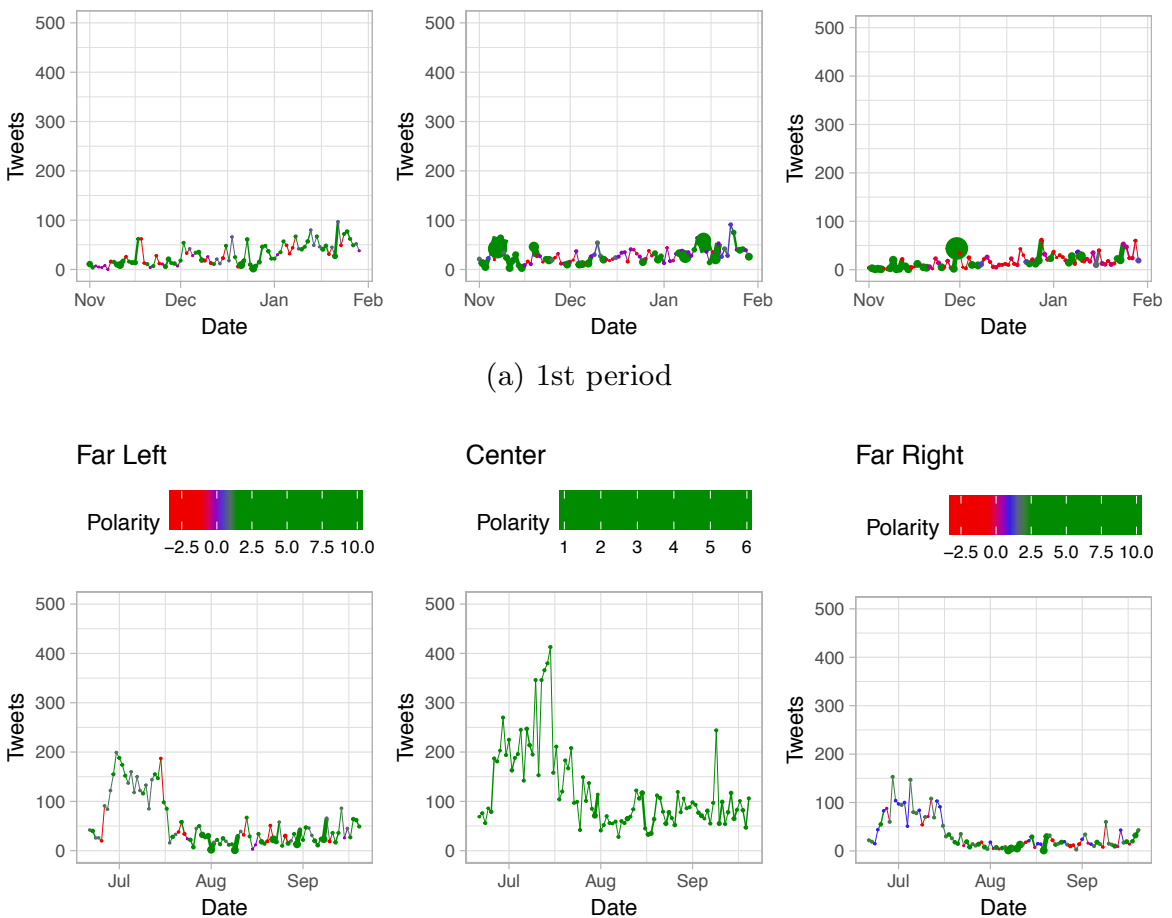

\section{Center}

Far Right
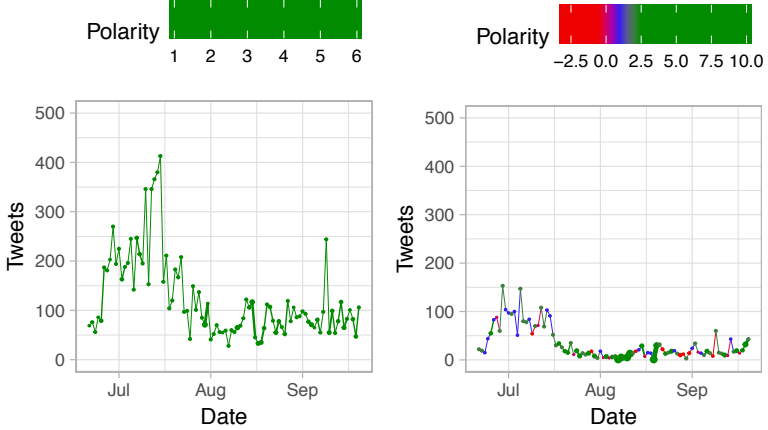

(b) 2nd Period
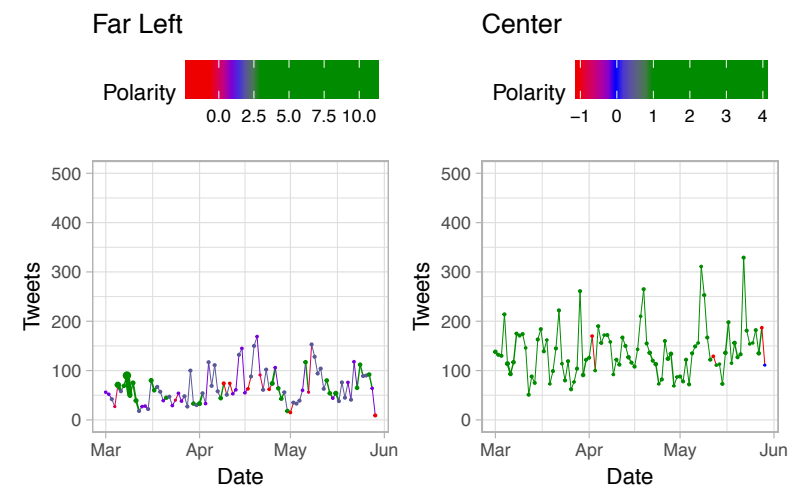

Far Right
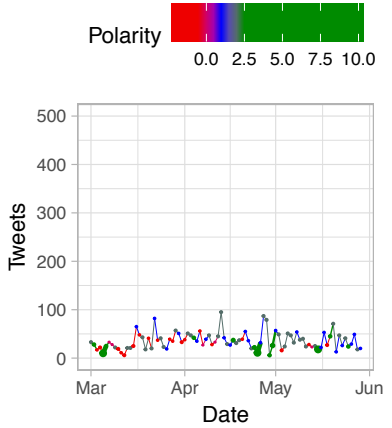

(c) 3rd period

Fig. 5: Sentiment Intensity (Color) and Tweets Volume ( $y$ axis) in the Replies within Political Spaces for all periods 


\section{References}

1. Agathangelou, P., Katakis, I., Koutoulakis, I., Kokkoras, F., Gunopulos, D.: Learning patterns for discovering domain oriented opinion words. Knowledge and Information Systems (2017)

2. Ball-Rokeach, S., DeFleur, M.: A dependency model of mass-media effects. Communication Research 3(1), 3-21 (1976)

3. Barberá, P.: Birds of the same feather tweet together. bayesian ideal point estimation using twitter data. Political Analysis 23(1), 76-91 (2015)

4. Barberá, P., Jost, J.T., Nagler, J., Tucker, J.A., Bonneau, R.: Tweeting from left to right is online political communication more than an echo chamber? Psychological Science (2015)

5. Bright, J.: Explaining the emergence of echo chambers on social media: the role of ideology and extremism. CoRR abs/1609.05003 (2016)

6. Bucher, T.: The friendship assemblage. Television \& New Media 14(6), 479-493 (2013)

7. Davou, B., Demertzis, N.: Feeling the Greek Financial Crisis, pp. 93-123. Palgrave Macmillan UK, London (2013)

8. Dinas, E., Rori, L.: The 2012 greek parliamentary elections: Fear and loathing in the polls. West European Politics 36(1), 270-282 (2013)

9. Fang, P., Liu, M., Xue, Y., Yao, J., Zhang, Y., Shen, H., Yang, P.: Controlling nonspecific trypsin cleavages in lc-ms/ms-based shotgun proteomics using optimized experimental conditions. Analyst 140, 7613-7621 (2015)

10. Holbert, R.L., Garrett, R.K., Gleason, L.S.: A new era of minimal effects? a response to bennett and iyengar. Journal of Communication 60(1), 15-34 (2010)

11. $\mathrm{Hu}$, M., Liu, B.: Mining and summarizing customer reviews. In: Proceedings of the Tenth ACM SIGKDD International Conference on Knowledge Discovery and Data Mining. pp. 168-177. KDD '04, ACM, New York, NY, USA (2004), http://doi.acm.org/10.1145/1014052.1014073

12. Kalyvas, S.: Modern greece: What everyone needs to know? (2015)

13. Kamps, J., Marx, M., Mokken, R.J., De Rijke, M., et al.: Using wordnet to measure semantic orientations of adjectives. In: LREC. vol. 4, pp. 1115-1118 (2004)

14. Lietz, H., Wagner, C., Bleier, A., Strohmaier, M.: When politicians talk: Assessing online conversational practices of political parties on twitter. arXiv preprint arXiv:1405.6824 (2014)

15. Lim, K.W., Buntine, W.: Twitter opinion topic model: Extracting product opinions from tweets by leveraging hashtags and sentiment lexicon. In: Proceedings of the 23rd ACM International Conference on Conference on Information and Knowledge Management (CIKM). pp. 1319-1328. ACM (2014)

16. Mutz, D.C.: Facilitating communication across lines of political difference: The role of mass media. American Political Science Review 95(1), 97114 (2001)

17. Qiu, G., Liu, B., Bu, J., Chen, C.: Expanding domain sentiment lexicon through double propagation. In: Proceedings of the 21st International Jont Conference on Artifical Intelligence. pp. 1199-1204. IJCAI'09, Morgan Kaufmann Publishers Inc., San Francisco, CA, USA (2009), http://dl.acm.org/citation.cfm?id=1661445.1661637

18. Ranganath, S., Hu, X., Tang, J., Liu, H.: Understanding and identifying advocates for political campaigns on social media. In: Proceedings of the Ninth ACM International Conference on Web Search and Data Mining. pp. 43-52. WSDM '16, ACM, New York, NY, USA (2016), http://doi.acm.org/10.1145/2835776.2835807 
19. dos Reis Costa, J.M., an Elizabeth Lindley Murnane, R.R., Choudhury, T.: It is not only about grievances: Emotional dynamics in social media during the brazilian protests. In: Proceedings of the Ninth International Conference on Web and Social Media, ICWSM 2015, University of Oxford, Oxford, UK, May 26-29, 2015. pp. $594-597(2015)$

20. Rori, L.: The 2015 greek parliamentary elections: from great expectations to no expectations. West European Politics 39(6), 1323-1343 (2016), http://dx.doi.org/10.1080/01402382.2016.1171577

21. Turney, P.D.: Thumbs up or thumbs down?: Semantic orientation applied to unsupervised classification of reviews. In: Proceedings of the 40th Annual Meeting on Association for Computational Linguistics. pp. 417-424. ACL '02, Association for Computational Linguistics, Stroudsburg, PA, USA (2002), http://dx.doi.org/10.3115/1073083.1073153

22. Vaccari, C., Valeriani, A., Barber, P., Jost, J.T., Nagler, J., Tucker, J.A.: Of echo chambers and contrarian clubs: Exposure to political disagreement among german and italian users of twitter. Social Media + Society 2(3), 2056305116664221 (2016), http://dx.doi.org/10.1177/2056305116664221

23. Van Gysel, C., Goethals, B., de Rijke, M.: Determining the presence of political parties in social circles. In: ICWSM. vol. 2015, pp. 690-693 (2015)

24. de Ziga, H.G., Valenzuela, S.: The mediating path to a stronger citizenship: Online and offline networks, weak ties, and civic engagement. Communication Research 38(3), 397-421 (2011) 